\title{
Sebastiano Bisson, Il fondo francese della Biblioteca Marciana di Venezia
}

\section{G. Matteo Roccati}

\section{Q OpenEdition}

1 Journals

\section{Edizione digitale}

URL: http://journals.openedition.org/studifrancesi/5512

DOI: 10.4000/studifrancesi.5512

ISSN: 2421-5856

\section{Editore}

Rosenberg \& Sellier

\section{Edizione cartacea}

Data di pubblicazione: 1 septembre 2011

Paginazione: 381

ISSN: 0039-2944

\section{Notizia bibliografica digitale}

G. Matteo Roccati, «Sebastiano Bisson, /l fondo francese della Biblioteca Marciana di Venezia », Studi Francesi [Online], 164 (LV | II) | 2011, online dal 30 novembre 2015, consultato il 10 janvier 2021. URL: http://journals.openedition.org/studifrancesi/5512 ; DOI: https://doi.org/10.4000/studifrancesi.5512

Questo documento è stato generato automaticamente il 10 janvier 2021.

\section{(c) (i) (9)}

Studi Francesi è distribuita con Licenza Creative Commons Attribuzione - Non commerciale - Non opere derivate 4.0 Internazionale. 


\title{
Sebastiano Bisson, Il fondo francese della Biblioteca Marciana di Venezia
}

\author{
G. Matteo Roccati
}

\section{NOTIZIA}

SEBASTIANO BISSON, Il fondo francese della Biblioteca Marciana di Venezia, Roma, Edizioni di Storia e Letteratura, 2008 («Sussidi eruditi», 76), XXVI-166 pp.

1 Il fondo francese (in realtà «straniero»: comprende anche codici in altre lingue), di cui la parte più antica proviene dalla collezione dei Gonzaga, arricchita da vari lasciti e acquisti, è costituito oggi da 110 codici. Il presente catalogo ne descrive 35 , cioè $i$ manoscritti medievali (anteriori al 1500) in francese, provenzale, franco-italiano. L'introduzione presenta il fondo e la sua storia e, su un corpus codicologico omogeneo di 27 codici (manoscritti provenienti dal nord Italia della fine XIII - inizio xv secolo), propone alcune considerazioni sulle caratteristiche di fabbricazione. Ogni manoscritto è oggetto di una descrizione materiale sobria e curata, il soggetto delle illustrazioni viene specificato, la bibliografia è deliberatamente «limitata alle edizioni principali e agli studi in cui sia privilegiata l'attenzione agli aspetti materiali del manoscritto» (p. XXIII), la storia del codice viene indicata in dettaglio. Le datazioni sono autonome e prudenti, qualche esempio fra i manoscritti più noti: Fr. 4 (V4), metà del xIV secolo (prima metà per Segre); Fr. 7 (V7), prima metà del XIV secolo (fine XIII per Segre); Fr. 9 (Guiron le Courtois), fine del XIII secolo (xIV per Lathuillère); Fr. 15 (Guiron le Courtois), metà del XIV secolo (XIV per Lathuillère); Fr. 17 (Benoît, V1), prima metà del xIv secolo (1330-1340 per Jung); Fr. 18 (Benoît, V2), metà del xIV secolo (XIV secolo per Jung). Alla fine del volume si trovano la tavola delle concordanze (dell'intero fondo), l'indice dei manoscritti e l'indice dei nomi e delle opere. 